\title{
ARTICLE OPEN \\ The potential role of land cover on secular changes of the hydroclimate of Peninsular Florida
}

\author{
Vasubandhu Misra ${ }^{1,2,3}$, Akhilesh Mishra ${ }^{1,4}$, Amit Bhardwaj $\mathbb{D i D}^{1,3}$, Krishnan Viswanathan ${ }^{5}$ and Dan Schmutz (iD ${ }^{6}$
}

The seasonal cycle of Peninsular Florida rainfall is a robust feature that has monsoon like seasonality. We objectively define the onset, demise, and length of the wet seasons over the time period of 1948-2006 in Peninsular Florida based on daily rainfall from the Climate Prediction Center of the National Centers for Environmental Prediction. This definition defines onset (demise) of the wet season of Peninsular Florida as the first day the daily accumulated precipitation anomaly reaches a minimum (maximum) for the year at a given grid point. A discernible linear trend of later onset, earlier demise, and a resulting shorter length of the wet season in urban areas relative to the rural areas is observed. The wet season accumulation of rainfall, however, does not reveal a proportional change in the linear trend implying a perceptible contrast of comparatively higher (lower) linear trend of the daily rain rate of the wet season over urban (rural) areas of Peninsular Florida.

npj Climate and Atmospheric Science (2018)1:5 ; doi:10.1038/s41612-018-0016-x

\section{INTRODUCTION}

The peninsular geography of Florida and its close proximity to the equator offers it a unique climate that has a distinct wet season. ${ }^{1}$ It is one of the wettest regions of the continental US ${ }^{2}$ that also experiences a fair share of extreme wet events from land falling tropical cyclones. ${ }^{3-5}$

Florida, owing to its relatively mild climate has witnessed an explosive growth in its population in the twentieth Century, expanding at $20-80 \%$ per decade. ${ }^{6}$ This high growth rate was stymied slightly by the great recession in the first decade of the new century, and the population is now anticipated to reach 23 million by $2030 .^{7}$ This increased population then feeds back to development, manifesting in changing land cover from construction of transportation infrastructure to converting forest and grass lands for agricultural, residential, commercial, and industrial purposes. $^{8-10}$ There have been a number of studies that have indicated the impact of land cover change on local climate. ${ }^{11-14}$ For example, Marshall ${ }^{15}$ found that drainage and conversion of wetlands to agricultural land could increase the likelihood of the frequency, severity, and duration of freezes in south Florida. Similarly, Misra et al. $^{13}$ found that the temperature trends for urban and rural regions of the southeastern US were different because of the contrasting impact of the land cover types in the two regions.

In this study, we explore the impact of land cover type on the hydroclimate trends in Peninsular Florida. More particularly, we are interested in examining the spatial variations in the trends of the onset date, demise date, and length of the wet season of Peninsular Florida and explore any of its functionalities to the underlying land cover types. There have been a growing number of recent studies that suggest the role of the impervious surface of urban areas in modulating rainfall. ${ }^{16-19}$ For example, Shepherd et al. ${ }^{17}$ using Tropical Rainfall Measuring Mission (TRMM) found a significant increase in warm season rainfall, 30-60 km downwind of major metropolitan cities in the southern United States. Similarly, Niyogi et al. $^{19}$ find that summer monthly rainfall amounts display an increasing trend in urbanized regions especially in the northeastern and mid-western United States. In examining the spatio-temporal patterns of warm season rainfall over Atlanta, McLeod et al. ${ }^{20}$ found that the increase in the early evening rainfall coincided with the warming of the surface temperature from the urban heat island effect, which in turn increased convective forcing. Mitra and Shepherd ${ }^{21}$ additionally identified enhanced moisture convergence from the increased roughness of the urban land cover, enhanced aerosols in urban environments serving as cloud condensation nuclei, and splitting of precipitating systems by the urban canopy as ways by which urban environments can influence rainfall. In the following section, we discuss the methodology and the datasets used followed by the discussion of results in "Discussion." Conclusions are presented in "Methods."

\section{RESULTS}

The relative growth in urbanization across the three decades in the Tampa-Orlando corridor, southeast Florida (around Miami), and around Jacksonville is most apparent in Supplementary Fig. S1 with a corresponding shrinkage in the rural land cover from 1980 to 2000. Most of this growth in urbanization in Florida is attributed to population growth. ${ }^{22-24}$ Rapid population growth caused changes in land cover from the development of transportation infrastructure, residential, commercial, and industrial complexes, as evident in the growth of the urbanization from 1980 to 2000 in the I-4 corridor connecting Tampa to Orlando (Supplementary Fig. S1a-c). Evaluating a similar time scale at a finer spatial resolution, Kautz et al. ${ }^{25}$ reported 0.61 million ha of

\footnotetext{
${ }^{1}$ Center for Ocean-Atmospheric Prediction Studies, Florida State University, Tallahassee, FL, USA; ${ }^{2}$ Department of Earth, Ocean and Atmospheric Science, Florida State University, Tallahassee, FL, USA; ${ }^{3}$ Florida Climate Institute, Florida State University, Tallahassee, FL, USA; ${ }^{4}$ Amity Center for Ocean-Atmosphere Science and Technology, Amity University, Jaipur, Rajasthan, India; ${ }^{5}$ Cambridge Systematics, Inc, Tallahassee, FL, USA and ${ }^{6}$ Greenman-Pedersen, Inc, Orlando, FL, USA

Correspondence: Vasubandhu Misra (vmisra@fsu.edu)
}

Received: 31 May 2017 Revised: 18 September 2017 Accepted: 20 September 2017

Published online: 09 April 2018 
natural and semi-natural land cover types present in Florida in 1985-89 were converted to urban and developed lands (representing $6.2 \%$ of all natural land cover types available at the beginning of the period).

The linear trends in the onset date, demise date, length, and seasonal accumulation of rainfall of the wet season over Peninsular Florida are shown in Fig. 1a, b, c, and d respectively. It is apparent from the figure that there are significant

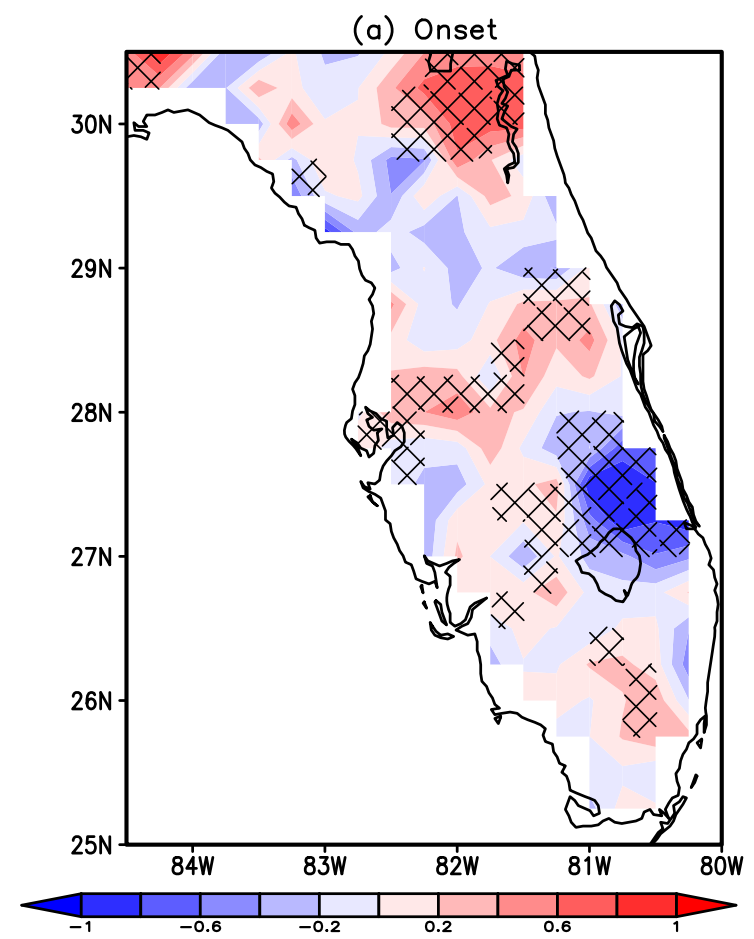

(b) Demise
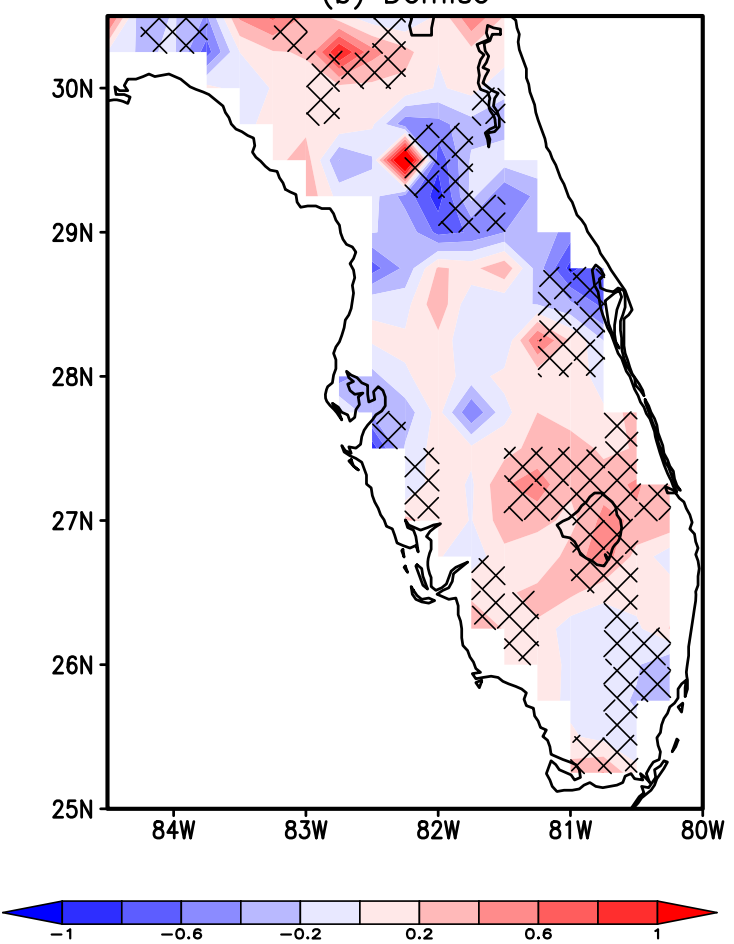

heterogeneities in the linear trends both in terms of magnitude and sign of all four variables. For example, strong negative trends in the onset date (Fig. 1a) near Vero Beach (suggestive of a tendency for earlier onset date in recent times relative to earlier periods) is adjacent to positive trends over Orlando just north of it. Likewise, there are apparent hotspots of rising and declining trends in other regions of Peninsular Florida in all four variables (Fig. 1).

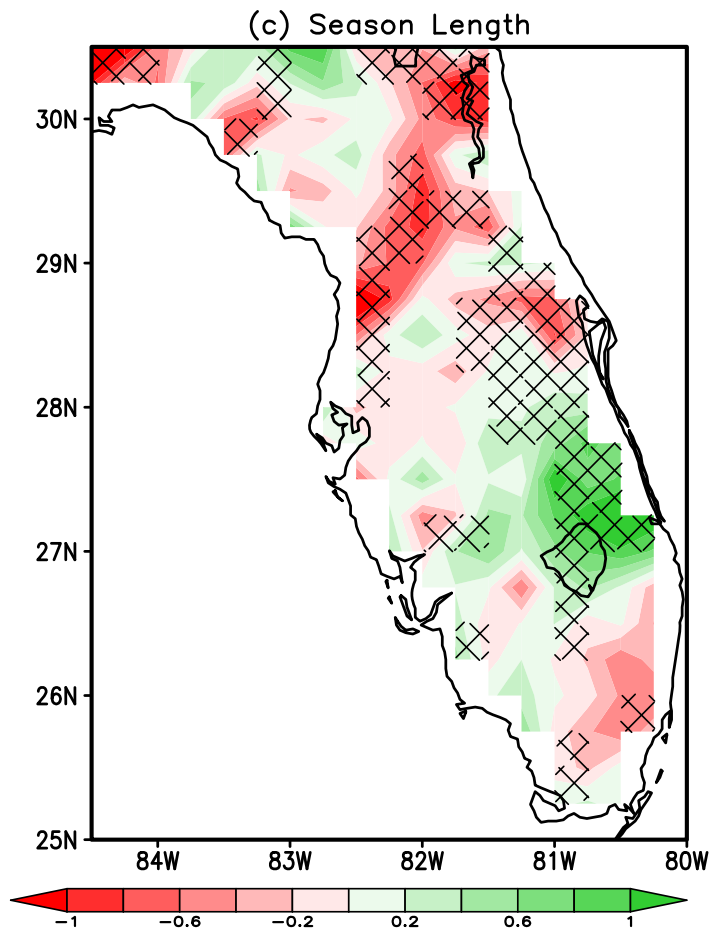

(d) Seasonal Accumulated Rain
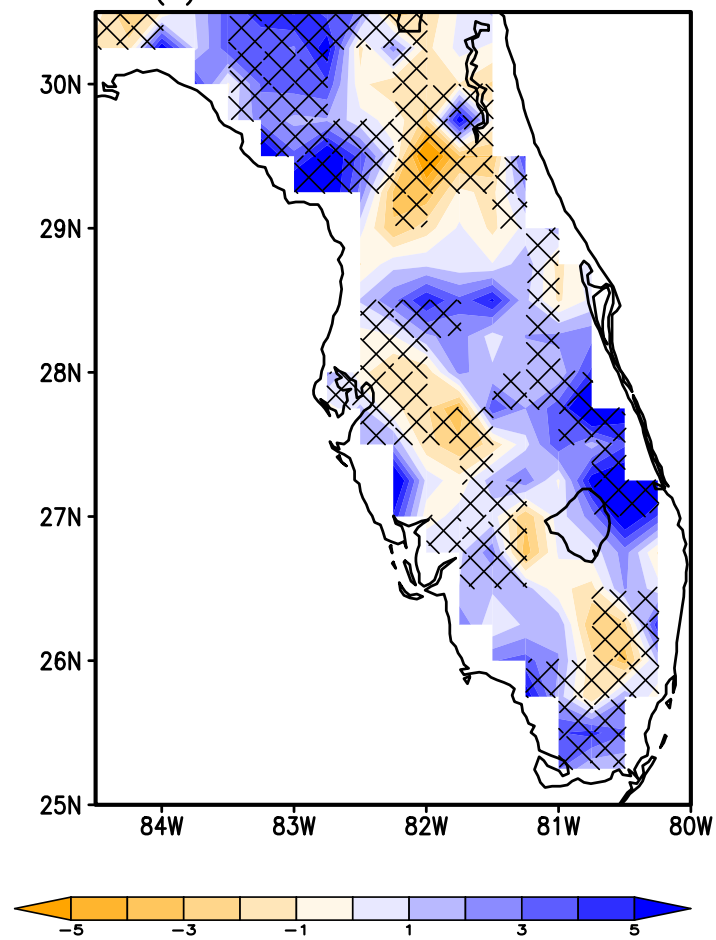

Fig. 1 The observed linear trends (shaded) in a onset (days/year), b demise (days/year) dates, c seasonal length (days/year), and d accumulated rainfall ( $\mathrm{mm} /$ year) of the wet season. The hatched regions indicate passing the Mann-Kendall test for significance $(p \leq 0.05)$ 
These trends of precipitation are overlaid on the populationinteraction zones for agriculture (PIZA) index of 2000 in Supplementary Fig. S2a-d. In considering the distribution of the PIZA index, say for a given year like 2000, we observe that there seems to be a pattern of a trend of later onset date (Supplementary Fig. S2a), earlier demise date (Supplementary Fig. S2b), and thereby shorter seasonal length (Supplementary Fig. S2c) of the wet season over some of the major urban areas (e.g. Tampa, Orlando, Miami, and Jacksonville) in Peninsular Florida. But a pattern in the trends of the seasonal rainfall accumulation of the wet season coherent with the land-surface type is not so apparent (Supplementary Fig. S2d). For example, Tampa region exhibits a declining trend while Orlando exhibits an increasing trend in the seasonal accumulation of the wet season rainfall. Previously, Mishra and Lettenmaier ${ }^{26}$ found that the rain rates in urban areas show an increasing trend in the US. A similar feature also has been observed in other urban regions when the study was expanded globally. ${ }^{27}$ However, Mishra and Lettenmaier ${ }^{28}$ find that unlike the trends in surface temperature the trends of precipitation in urban areas of US show far less frequent statistical significance, which they attribute to the result of higher natural variability on the latter compared to the former.

These patterns of secular changes in the wet season parameters with land type is further confirmed in Fig. 2, which shows the scatter of the linear trends in the onset date, demise date, seasonal length, and seasonal rainfall accumulation of the wet season with the PIZA index for the year 2000. In order to get an unbiased estimate of the linear fit of the trends in the variables of the wet season with the PIZA index, we ensured that there were equal numbers of counties for each PIZA category. We iterated (bootstrapped) the scatter by randomly picking the same (equal) number of counties for each PIZA index for 10,000 iterations to develop the $95 \%$ confidence interval for the slope of the linear fit as shown in Fig. 2. It is quite apparent from this figure that a trend of later onset date, early demise date, and thereby shorter seasonal length is preferentially more prominent in counties with PIZA index of 4 (highly urbanized) compared to the more rural regions (PIZA index of 1 ). Additionally, it may be noted that the rate of increase in the linear trend of the occurrence of later onset date of the wet season with increase in PIZA index is significantly higher (Fig. 2a) than that of the occurrence of the earlier demise date of the wet season with increase in the PIZA index (Fig. 2b). Similarly, we find that the rate of change in the seasonal rainfall accumulation of wet season with PIZA index (Fig. 2d) is proportionately much weaker than that for the rate of change in the seasonal length (Fig. 2c). This implies that the average daily rain rate for the wet season is rising more in the urban regions relative to the rural regions. We know this because despite the comparatively strong shortening of the seasonal length of the wet season in the urban regions the seasonal accumulation continues to decrease far more moderately, thereby causing the average daily rain rate to increase. These findings are consistent with other recent studies that indicate a rising trend in extreme precipitation events in the southeastern United States including Florida. ${ }^{29,30}$ These studies attribute the likely cause to increasing water vapor content in the atmosphere with rising temperature trend on account of global warming. In another related study, Mishra and Lettenmaier $^{28}$ find that there is a rising trend in the daily precipitation maximum and in the frequency of extreme daily precipitation in urban areas across the US. They state that the attribution of these trends in urban precipitation is far more complex than a similar rising trend in minimum temperature in urban areas of the US, which is attributed to the urban land cover effect. $^{28,31}$ (a) Onset
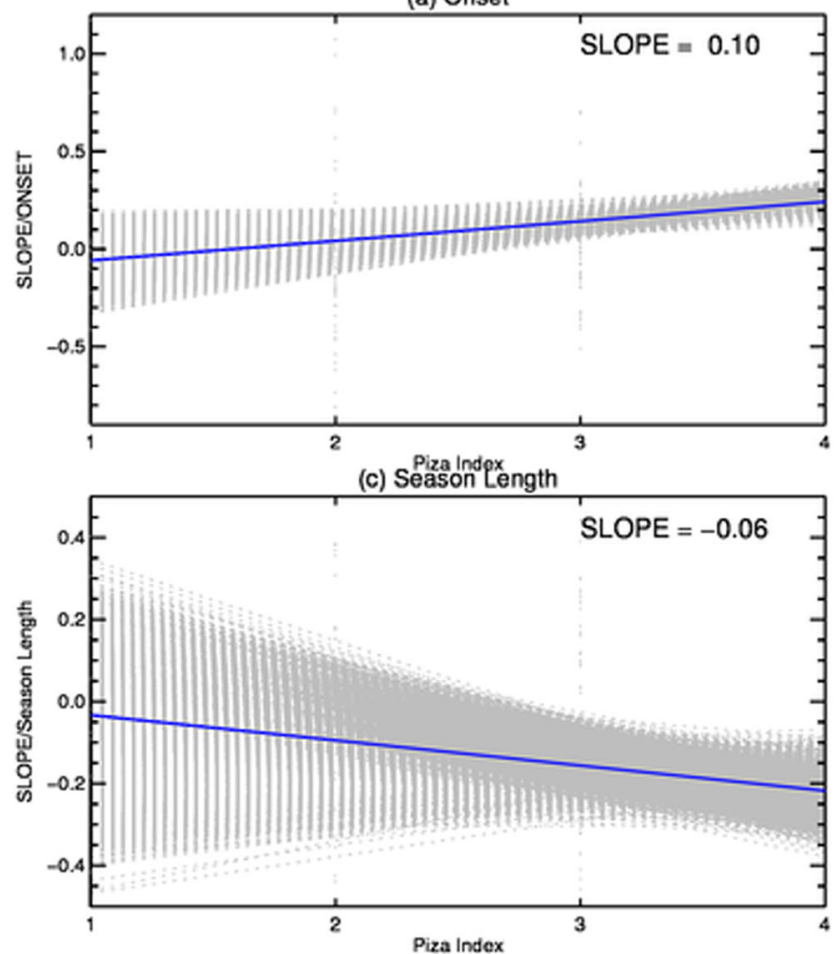

(b) Demise

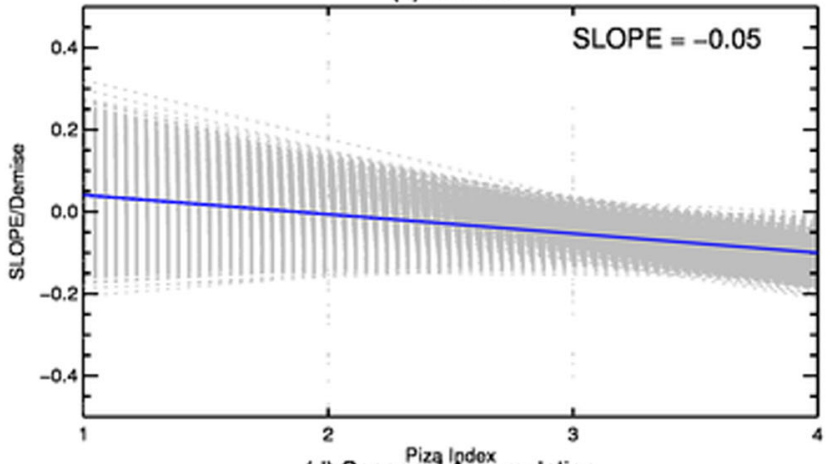

(d) Seasonal Accumulation

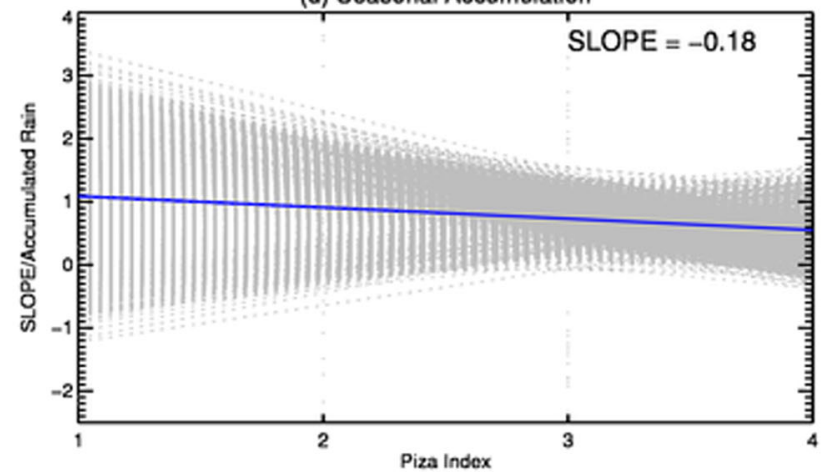

Fig. 2 The scatter of the linear trend of $\mathbf{a}$ onset date, $\mathbf{b}$ demise date, $\mathbf{c}$ length, and $\mathbf{d}$ seasonal accumulation of wet season rainfall over peninsular Florida with PIZA index is plotted. The units of the slope of the linear fit to the scatter (blue line with median slope) in the three panels (a, b, and $\mathbf{c})$ is days/year/PIZAindex and for seasonal rainfall accumulation (bottom left) is $\mathrm{mm} / \mathrm{season} / \mathrm{year} / \mathrm{PIZAindex}$. The gray shaded lines represent the $95 \%$ confidence interval of the linear fit 

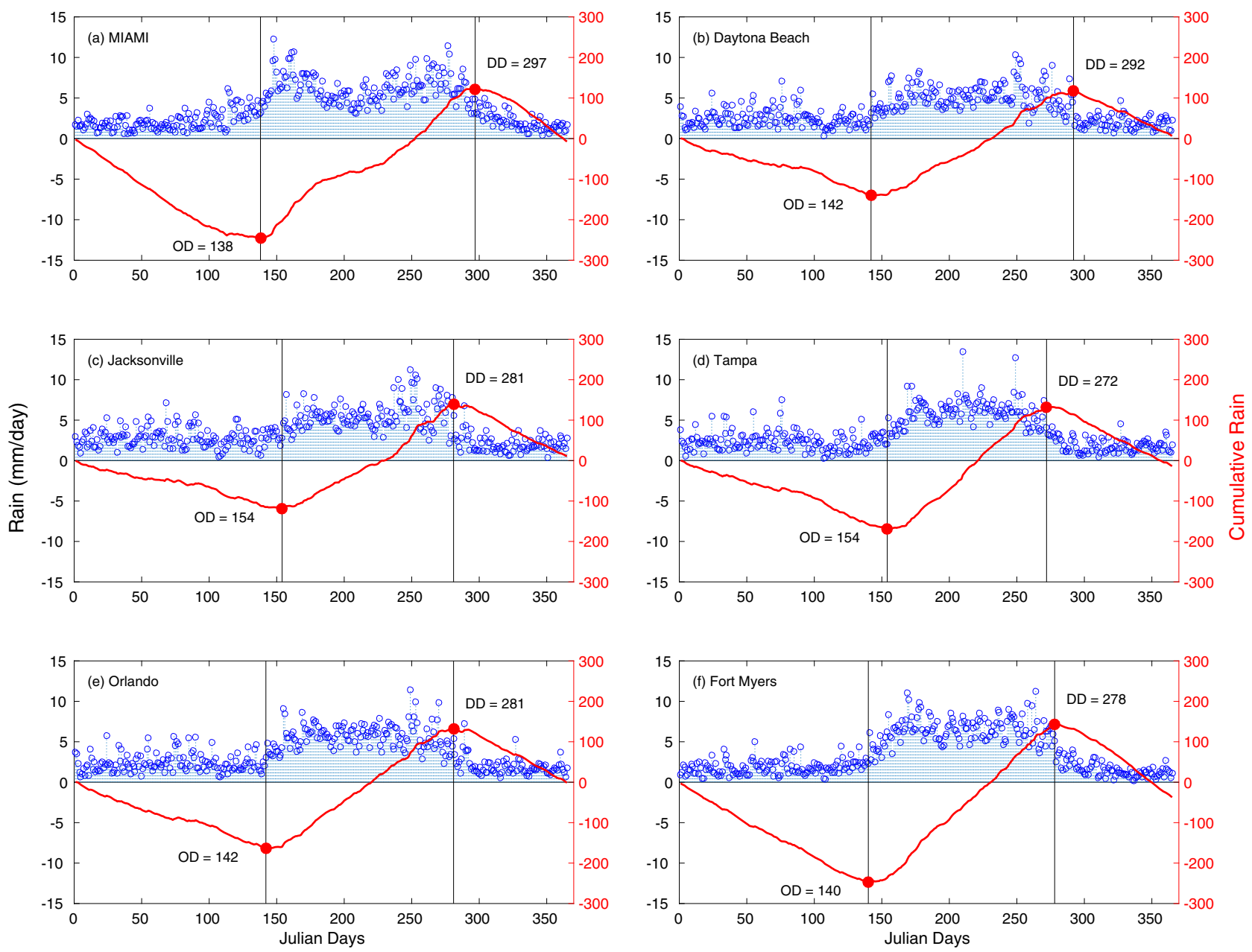

Fig. 3 The time series of the climatological daily rainfall (red) and the corresponding accumulated daily rainfall anomaly (blue) with onset (OD) and demise (DD) date indicated (in Julian day) for a Miami, b Daytona Beach, c Jacksonville, d Tampa, e Orlando, and f Fort Myers

\section{DISCUSSION}

Peninsular Florida is well known for its distinct wet season that has a well-defined onset and demise date from the southern tip to northern parts of the Panhandle. In this paper, we clearly show that the linear trends of onset date, demise date, seasonal length, and seasonal rainfall accumulation of the wet season are rather heterogeneously distributed across Peninsular Florida. However, this heterogeneity of the rainfall trends in the parameters of the wet season seems to be coherent with the land-surface type. It is also possible to interpret the observed trends of the wet season of Peninsular Florida as a response to change in land cover if we assume that the land-surface type of 2000 reflects the change over the period of 1948-2000. We find that a trend of later onset date, earlier demise, and thereby shorter seasonal length is most prevalent in the most urbanized regions relative to the rural regions of Peninsular Florida. Interestingly, the trends in the seasonal rainfall accumulation are not so consistent with the landsurface type. This inconsistency results in a significant increasing trend of average daily rain rate in the shortened wet season over the urbanized regions of Peninsular Florida.

It is beyond the scope of this paper to understand the actual causes of such a pattern in secular changes of the wet season with land-surface type. There are some studies, which do allude to regional increase in summer temperatures and decrease in precipitation due to conversion of land surface from agricultural land to urban land form. ${ }^{11,12,28,32}$ In a more recent study Misra and Mishra $^{32}$ conducted a detailed moisture budget on model simulations of Florida's wet season that indicated moisture flux convergence is dominant at the time of the onset of the wet season, while local recycling of moisture becomes equally important in the rest of the wet season. Therefore, changes in boundary layer convergence from changes to roughness length in land-surface type could trigger such impacts on the wet season as seen in this paper. On the other hand, it is possible that the moderate changes in surface evaporation rates, even if they are comparably smaller than moisture flux convergence, from changes in land-surface type could be sufficient to modulate the onset of the wet season. It is suggested from earlier studies ${ }^{33,34}$ that urban land cover of coastal cities could potentially enhance rainfall through sea breeze-urban interactions. These aspects would have to be discerned from detailed numerical modeling studies that examine the sensitivity of the evolution of the wet season of Peninsular Florida to land cover changes.

\section{METHODS}

We used the unified daily US precipitation analysis of the Climate prediction center available at $0.25^{\circ}$ resolution $^{35}$ from $1948-2006$. This gauge analysis dataset covers the conterminous United States, and it includes rain gauge data from the National Weather Service Cooperative Observer Program (https://www.ncdc.noaa.gov/data-access/land-basedstation-data/land-based-datasets/cooperative-observer-network-coop), river forecast centers, and the National Centers for Environmental Information. 
Following Misra and DiNapoli, ${ }^{1}$ we define the onset and demise of the wet season as points in the time series when the accumulated daily rainfall anomaly $\left(\mathrm{O}^{\prime}\right)$ reaches a minimum and a maximum during the year respectively. $\mathrm{O}^{\prime}$ is given as:

$$
O \prime=\sum_{l=1}^{\text {NDAYS }}\left\{D_{k}(I)-\overline{\bar{D}}\right\}
$$

where, $D_{k}(l)$ is the daily rainfall for the $k$ th year on the /th day and $\overline{\bar{D}}$ is climatological annual mean average rainfall. An illustration of the diagnosis of onset and demise dates of the rainy season based on daily rainfall climatology for Miami, Daytona Beach, Jacksonville, Tampa, Orlando, and Ft. Myers is shown in Fig. 3. In addition, the length of the wet season can be defined as the difference between the demise and onset dates. It may be noted that Eq. (1) can be applied at every given grid point of the dataset. We, however, restrict ourselves to Peninsular Florida as it exhibits a robust seasonal cycle, for which this objective definition of onset, demise works the best. ${ }^{1}$

We follow $\mathrm{Ji}$ et $a .^{36}$ to isolate the trends in the onset, demise, and the length of the wet season. They employed the Ensemble Empirical Mode Decomposition (EEMD ${ }^{37,38}$ ) a data-adaptive time series technique that does not use any predetermined basis functions to isolate the trends in surface temperature. This method unambiguously removes all oscillatory components (referred to as the intrinsic mode functions [IMFs]) within the time span of the given data series and retains as residue a monotonic function (or the component with secular change) with at most one extremum over the given time period. These residuals were generated from a 100-member EEMD. As noted in Wu and Huang, ${ }^{37}$ in order to avoid mode mixing of various frequencies, the IMF's are obtained from an ensemble average of over 100 trials, with each trial obtained by adding a Gaussian white noise to the original time series. Therefore, the residual is an ensemble mean of 100 such trials. We then computed the trend by fitting a least square linear fit to the residual component. The slope of this linear fit is then tested for significance using the non-parametric MannKendall test. ${ }^{39}$ Supplementary Fig. S3 shows an example of this method depicting the raw time series of the onset of the rainy season for the 59 years for the grid point closest to Jacksonville and its IMF components including its residual component and the linear fit to this component.

We also used the PIZA developed by the US Department of Agriculture Economic Research Service ${ }^{40}$ as a proxy for land cover. This has been used in the past for land cover change studies. ${ }^{13,14}$ PIZA essentially indexes the influence of urban-related activities (including residential, commercial, and industrial) on agricultural land use. The PIZA code is derived from population-interaction index (PII), which provides a measure of potential interaction between nearby urban-related population and agricultural production activities, by effectively ranking each location or an area on a continuous scale from 1 to 4 . The PIZA uses a four index category classification, one being rural and four urban with two and three in the transition. The PIZA index is provided at the granularity of the county lines. There are 67 counties in Florida with 45 counties in Peninsular Florida. The PIZA data is provided for three decades (1980, 1990, 2000; https://www.ers. usda.gov/data-products/population-interaction-zones-for-agriculture-piza/) as shown in Supplementary Fig. S1.

\section{Data availability statement}

The rainfall data used in this study is publicly available from https://www. esrl.noaa.gov/psd/data/gridded/data.unified.daily.conus.html/. Similarly, PIZA index is publicly available from https://www.ers.usda.gov/dataproducts/population-interaction-zones-for-agriculture-piza/.

\section{ACKNOWLEDGEMENTS}

This work was supported by NOAA grant NA12OAR4310078 and a grant of the South Florida Water Management District (PO 039231).

\section{AUTHOR CONTRIBUTIONS}

V.M. wrote the main manuscript text, A.B. and A.K.M. prepared Figures 1-3 and S1-S3. K.V. helped in the analysis and preparation of the PIZA data and D.S. helped in the interpretation of the results and editing of the manuscript with the rest of the authors. All authors reviewed the manuscript.

\section{ADDITIONAL INFORMATION}

Supplementary information accompanies the paper on the npj Climate and Atmospheric Science website (https://doi.org/10.1038/s41612-018-0016-x).

Competing interests: The authors declare no competing interests.

Publisher's note: Springer Nature remains neutral with regard to jurisdictional claims in published maps and institutional affiliations.

\section{REFERENCES}

1. Misra, V. \& S. DiNapoli, S. Understanding wet season variations over Florida. Clim. Dyn. 40, 1361-1372 (2013).

2. Chan, S. \& Misra, V. A diagnosis of the 1979-2005 extreme rainfall events in the southeastern United States with isentropic moisture tracing. Mon. Wea. Rev. 138 1172-1185 (2010).

3. Knight, D. B. \& Davis R. E. Contribution of tropical cyclones to extreme rainfall events in the southeastern United States. J. Geophys. Res. Atmos. 114, D23102. https://doi.org/10.1029/2009JD012511 (2009).

4. Maxwell, J. T., Soulé, P. T., Ortegren, J. T. \& Knapp, P. A. Drought-busting tropical cyclones in the southeastern Atlantic United States: 1950-2008. Ann. Assoc. Am. Geogr. 102, 259-275 (2012).

5. Maxwell, J. T., Ortegren, J. T., Knapp, P. A. \& Soulé, P. T. Tropical cyclones and drought amelioration in the Gulf and southeastern coastal United States. J. Clim. 26, 8440-8452 (2013).

6. Smith, S. K. Florida Population Growth: Past, Present and Future. Research report by the Bureau of Economic and Business Research (University of Florida, Florida Climate Institute, Tallahassee, Florida, 2005). Retrieved from: https://www.bebr. ufl.edu/sites/default/files/Research\%20Reports/FloridaPop2005_0.pdf.

7. Carlson, E. in Climate Scenarios: A Florida-Centric View (ed. V. Misra) (Florida Climate Institute, Tallahassee, Florida, 2012). Available from:http://floridaclimate. org/climate_scenario_pdf.php.

8. Derr, M. Some Kind of Paradise: A Chronicle of Man and the Land in Florida. (Gainesville, University Press of Florida, 1998).

9. City of Miami, City of Miami History. Retrieved from http://www.miamigov.com/ home/history.html (2015).

10. Turner, G. A Short History of Florida Railroads (Arcadia Publishing, Charleston, S. C., 2013).

11. Pielke, R. A. et al. The influence of anthropogenic landscape changes on weather in South Florida. Bull. Am. Meteorol. Soc. 127, 1663-1673 (1999).

12. Marshall, C. H., Pielke, R. A., Steyaert, L. T. \& Willard, D. A. The impact of anthropogenic land-cover change on the Florida Peninsula sea breezes and warm season sensible weather. Bull. Am. Meteorol. Soc. 132, 28-52 (2004).

13. Misra, V. et al. Reconciling the spatial distribution of the surface temperature trends in the southeastern United States. J. Clim. 25, 3610-3618 (2012).

14. Misra, V. \& Michael, J. P. Varied diagnosis of the observed surface temperature trends in the southeast US. J. Clim. 26, 1467-1472 (2012).

15. Marshall, C. H., Pielke, R. A. \& Steyaert, L. T. Wetlands: Crop freezes and land-use change in Florida. Nature 426, 29-30 (2003).

16. Bornstein, R. \& Lin, Q. Urban heat islands and summertime convective thunderstorms in Atlanta: three case studies. Atmos. Environ. 34, 507-516 (2000).

17. Shepherd, J. M., Harold, P. \& Negri, A. J. On rainfall modification by major urban areas: Observations from space-borne radar on TRMM. J. Appl. Meteorol. 41, 689-701 (2002).

18. Ashley, W. S., Bentley, M. L. \& Stallins, J. A. Urban-induced thunderstorm modification in the southeast United States. Clim. Change 113, 481-498 (2012).

19. Niyogi, D., Lei, M., Kishtawal, C., Schmid, P. \& Shepherd, M. Urbanization impacts on the summer heavy rainfall climatology over the Eastern United States. Earth Interact. 21, 5-17 (2017).

20. McLeod, J. T., Shepherd, M. \& Konrad, C. Spatio-temporal rainfall patterns around Atlanta, Georgia and possible relationships to urban land cover. Urban Clim. https://doi.org/10.1016/j.uclim.2017.03.004 (2017).

21. Mitra, C., \& Shepherd, M. in The Routledge Handbook of Urbanization and Global Environment Change. 152-168 (Routledge, Abington, Oxford, England, 2016).

22. Kautz, R., Stys, B. \& Kawula, R. Florida vegetation 2003 and land use change between 1985-89 and 2003. Fla. Sci. 70, 12-23 (2007).

23. Reynolds, J. E. in Current Issues Associated with Land Values and Land Use Planning Proceedings of a Regional Workshop (ed. J. C. Bergstrom) 28 (Southern Rural Development Center and Farm Foundation, Mississippi State, USA, 2001).

24. Carr, M. \& Zwick, P. Florida 2070 Mapping Florida's Future - Alternative Patterns of Development in 2070. Technical Report (1000 Friends of Florida, Tallahassee, Florida, 2016).

25. Kautz, Randy S. Land use and land cover trends in Florida 1936-1995. Fla. Sci. 61, 171-187 (1998) 
26. Mishra, V. \& Lettenmaier, D. P. Climatic trends in major U.S. urban areas, 1950-2009. Geophys. Res. Lett. 38, L16401 (2011).

27. Mishra, V., Ganguly, A. R., Nijssen, B. \& Lettenmaier, D. P. Changes in observed climate extremes in global urban areas. Env. Res. Lett. 10, https://doi.org/10.1088/ 1748-9326/10/2/024005 (2015).

28. Kalnay, E. \& Cai, M. Impact of urbanization and land-use change on climate. Nature 423, 528-531 (2003).

29. Kunkel, K. E. et al. Monitoring and understanding trends in extreme storms. Bull. Am. Meteorol. Soc. 94, 499-514 (2013).

30. Wuebbles, D. J. et al. CMIP5 climate model analyses: Climate extremes in the United States. Bull. Am. Meteorol. Soc. 95, 571-583 (2014).

31. Easterling, D. R. et al. Climate extremes: Observations, modeling, and impacts. Science 289, 2068 (2000).

32. Misra, V. \& Mishra, A. K. The oceanic influence on the rainy season of Peninsular Florida. J. Geophys. Res.: Atmospheres. 121, 7691-7709 (2016).

33. Shepherd, J. M., Ferrier, B. S. \& Ray, P. S. Rainfall morphology in Florida convergence zones: a numerical study. Mon. Weather Rev. 129, 177-197 (2001).

34. Shepherd, J. M., Carter, W. M., Manyin, M., Messen, D. \& Burian, S. The impact of urbanization on current and future coastal convection: a case study for Houston. Environ. Plan. 37, 284-304 (2010).

35. Higgins, R. W., Shi, W., Yarosh, E. \& Joyce, R. Improved United States precipitation quality control system and analysis. NCEP/ CPC ATLAS No. 7. 40, http://www.cpc. ncep.noaa.gov/research_papers/ncep_cpc_atlas/7/toc.html (2000).

36. Ji, F., Wu, Z., Huang, J. \& Chassignet, E. P. Evolution of land surface air temperature trend. Nat. Clim. Change 4, 462-466 (2014).

37. Wu, Z. H. \& Huang, N. E. Ensemble empirical mode decomposition: a noise 249 assisted data analysis method. Adv. Adapt. Data Anal. 1, 1-41 (2009).
38. Wu, Z., Huang, N. E., Wallace, J. M., Smoliak, B. V., \& Chen, X. On the time-varying 2 trend in global mean surface temperature. Clim. Dyn. https://doi.org/10.1007/ s00283-011-1128-8 (2011).

39. Sneyers, R. On the statistical analysis of series of observations. Technical note 143, WMO no. 415. 192 (World Meteorological Organization, Geneva, Switzerland, 1990).

40. USDA-ERS, Available online at: http://www.ers.usda.gov/Data/ PopulationInteractionZones/overview.htm/S (2005).

(i) Open Access This article is licensed under a Creative Commons Attribution 4.0 International License, which permits use, sharing, adaptation, distribution and reproduction in any medium or format, as long as you give appropriate credit to the original author(s) and the source, provide a link to the Creative Commons license, and indicate if changes were made. The images or other third party material in this article are included in the article's Creative Commons license, unless indicated otherwise in a credit line to the material. If material is not included in the article's Creative Commons license and your intended use is not permitted by statutory regulation or exceeds the permitted use, you will need to obtain permission directly from the copyright holder. To view a copy of this license, visit http://creativecommons. org/licenses/by/4.0/.

(c) The Author(s) 2018 